\title{
Strength Enhancement of Car Front Bumper for Slow Speed Impact by FEA Method as per IIHS Regulation
}

\author{
Chandrakant Rameshchandra Sonawane ${ }^{1} \cdot$ Ajit Lavaji Shelar $^{2}$
}

Received: 29 February 2016/ Accepted: 28 March 2017/Published online: 11 May 2017

(C) The Institution of Engineers (India) 2017

\begin{abstract}
Low speed collisions happen significantly due to on road slow moving heavy traffic as well as during parking of vehicles. The bumpers are provided in front and back side of a vehicle has two main purposes: first is to absorb the energy generated during these kinds of slow speed impacts and secondly to protect the expensive parts like main engine parts, radiators and connected engine cooling mechanism, headlights, taillights, etc, by slowing down the vehicles. The problem often in various cars bumper is that they doesn't line-up vertically during low speed impact and leads to damage of various parts which are costly to repair. Many a times bumper design does not have sufficient capacity to absorb the energy generated during these impact. Guideline by International Institute Highway Safety (IIHS) regulation provides useful insight for such low speed impact study. In this paper, slow speed impact test were conducted as per IIHS regulation in three positions namely central impact, left hand corner impact and right hand corner impact. Parameters including bumper material, shape, thickness and impact condition are analyzed using fine element analysis (FEA) to enhance crashworthiness design in low speed impact. Then the vehicle front structure has been modified suitably. It has been observed that lining up the front metal bumper with suitable stiffness provides the best result which ultimately reduces the damage to the vehicle parts.
\end{abstract}

Keywords Bumper - Slow speed impact .

Finite element analysis - Impact energy · Crashworthiness

Chandrakant Rameshchandra Sonawane crsonawane@gmail.com

1 Department of Mechanical Engineering, Symbiosis Institute of Technology, Lavale, Pune 412115, Maharashtra, India

2 Echelon CAE Service Pvt Ltd, Pune 411041, Maharashtra, India

\section{Introduction}

In today's scenario, one of the greatest challenges faced by an automotive industry is to provide safer vehicles with high fuel efficiency at competitive cost. Automotive designs with economy, safety and aesthetics have been a great challenge to design engineers. Current automotive vehicle structures have one fundamental handicap, a short crumple zone for crash energy absorption. The safety of the passengers during vehicle crashes can be ensured to a certain limit by using good bumpers. Mainly bumpers are used to protect vehicle parts such as radiator, cooling systems, exhaust system, hoods and fenders headlights, taillights that are expensive to repair. At the same time this automotive part should not be massive in terms of weight contributing to the increase in total the weight of the vehicle. Hence the bumper provides safety as well as aesthetic look to the most of passenger vehicles.

Figure 1 shows the schematic view of vehicle front structure which mainly includes the outer plastic bumper, crush brackets and metal bumper. Outer plastic bumper provided for aesthetic look whereas the crush brackets and metal bumper supports during slow impact and protect nearby engines parts. Some car manufactures also provides the front and rear bumpers made up of metal sheet having material steel or aluminium alloy. Few auto makers design the bumper bar and its attachment brackets to crush in a slow speed crash to absorb energy. Now-a-days material like formed thermoplastic and polypropylene foam are also used in addition to or instead of crushable brackets and a bar.

Bumpers of colliding vehicles should line-up geometrically so that they engage each other during a low-speed crash to absorb crash or impact energy. Bumpers should stay engaged with the other bumpers in collisions instead of overriding or under riding them, which often results in damage to headlights, fenders hoods and trunks. Bumpers 


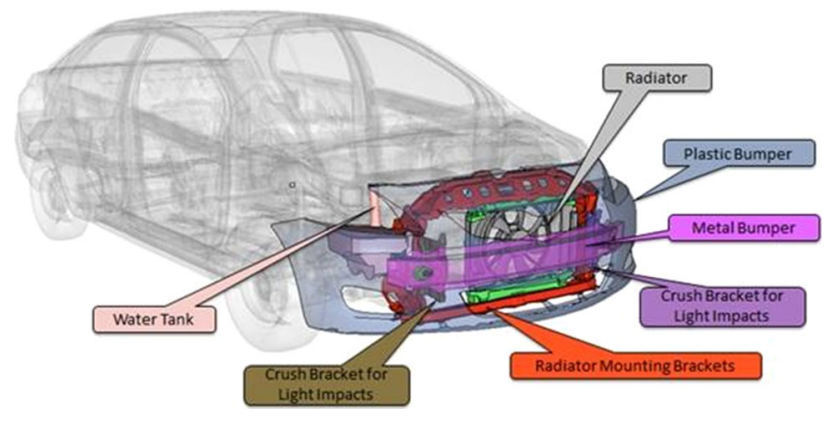

Fig. 1 Vehicle front structure

should have sufficient energy absorbing capabilities to con ne damage to the bumper system itself.

Marzbanrad, et al [1] studied a front bumper beam made of three different materials: aluminium, glass mat thermoplastic (GMT) and high-strength sheet moulding compound (SMC). The defection, impact force, stress distribution and energy-absorption behaviour of these three material bumper is studied by impact modelling using finite element analysis (FEA) explicit software. A finite element model of pendulum impact test is simulated. Their results shows that a modified SMC bumper beam can minimize the bumper beam deflection, impact force and stress distribution and maximize the elastic strain energy.

Hosseinzadeh, et al [2] studied a commercial front bumper beam made of GMT by impact modeling using LSDYNA software. The test conducted as per the ECE United Nations Agreement. Three main design factors: shape, material and impact conditions were studied and the results are compared with conventional metals like steel and aluminium. There study shows that GMT structure showed very good impact behaviour compared with other structures.

Magalhaes, et al [3] worked on a front bumper fascia using the BEM sub-model. Similarly Ge, et al [4] studied preliminary version of an evolutionary modeling approach (EMA) to generate surrogate (FEA) models for highly nonlinear system. Through an evolutionary process, less accurate surrogate models gradually evolve into more accurate ones as the quality of the sampling data set is improved.

Davoodi, et al [5] analyzed eight bumper beam having various cross sections concepts with the same material model under low impact test standard conditions. There study focused on energy absorption improvement by cross-section, material and manufacturing optimizations. Further they [6] show that the bumper beam absorbs the accidental kinetic energy by defection in low-speed impact and by deformation in high-speed impact. Few authors [7, 8] also analyzed for various materials, however lining up the front (or rear) metal bumper with suitable stiffness is need studied which can provides the better results during slow impact test.

The objective of this paper is to carry out the slow speed impact test as per International Institutes for Highway Safety
(IIHS) regulation in three different positions namely central impact, left hand corner impact and right hand corner impact. Analyze the contributing parameters like shape, pro le, thickness and impact condition using finite element analysis for car front parts to enhance crashworthiness design in low speed impact. Modify the vehicle front structure suitably to enhance crashworthiness, ensure passenger safety as well as with high strength to weight ratio through the impact analysis.

\section{IIHS Test Procedure Norms}

The Insurance Institute for Highway Safety (IIHS) [9] is scientific and educational independent organization dedicated to reducing the death losses, injuries and property damage from crashes on the nation's roads. The Institutes low-speed crash test series includes front and rear into at barrier impacts plus two localized impact tests. These crash tests provide information about how well various cars manage the energy of these impacts. Their tests [9] encourage for taller and more stable front bumpers to prevent front under-ride and wider bumpers to protect corners.

Figure 2 shows how actual full frontal impact and front corner impact test were conducted. As per IIHS [9], the configuration during these test are:

Full Frontal Test Configuration

(a) Height of barrier: $457 \mathrm{~mm}$ from the ground to the lower edge of the barrier.

(b) Speed of vehicle: $10 \mathrm{~km} / \mathrm{h}$.

Front Corner Test Configuration

(a) Height of barrier: $406 \mathrm{~mm}$ from the ground to the lower edge of the barrier.

(b) Speed of vehicle: $5 \mathrm{~km} / \mathrm{h}$.

(c) Overlap: $15 \%$ based on vehicle width at the front axle (excluding exterior mirrors, flexible mud flap sand lights).

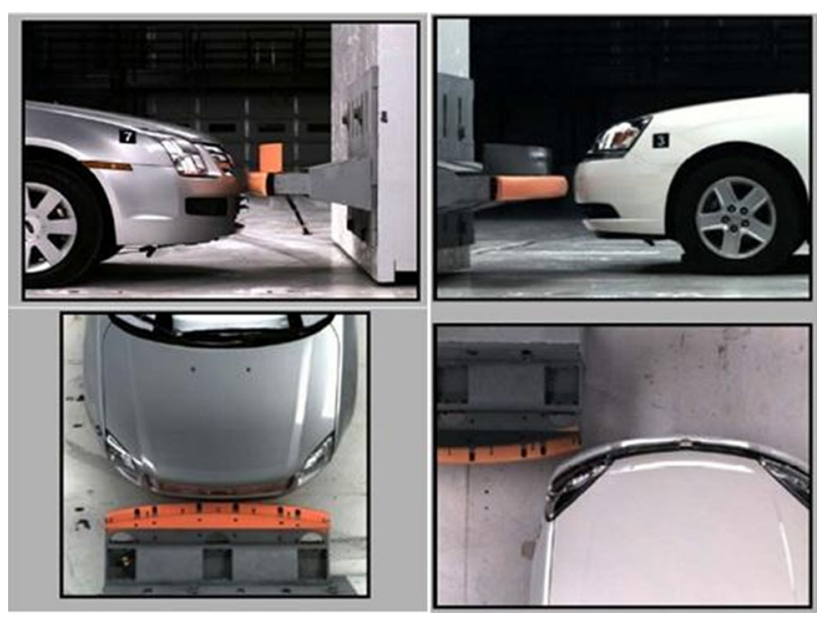

Fig. 2 Full frontal impact and front corner impact 


\section{Model Information}

The car model used in this paper is available and developed by the National Crash Analysis Center (NCAC) of the George Washington University under a contract with the Federal High Way Administration (FHWA) and National Highway Traffic Safety Administration (NHTSA) [10] of the United States Department of Transportation (USDOT). These models were developed for research purposes as documented [11] in the associated reports for each model.

The baseline model considered in this paper is a well corelated of Toyota Yaris 2010 [11]. Figures 3 and 4 [11] show the details of solid model and mesh generated view of car used for FE analysis, respectively. There are 771 numbers of parts, which are meshed using 998,218 numbers of nodes and 974,383 numbers of hybrid elements. Table 1 gives the detailed summary of mesh elements used and number of connections utilized for the analysis. As emphasis is laid down upon analysing the low speed impact on bumper which has material: Mat24 with material properties as mentioned in Table 2 [11]. During modelling, whenever necessary the mesh for metal bumper is made fine. The detailed list of all parts used, their material properties, geometric details, material testing details, etc, can be found in [11-13].

\section{Test Procedure for Impact Analysis}

As per IIHS recommendations, full overall impact and front corner impact test are considered. The baseline model considered here is a well co-related of Toyota Yaris 2010
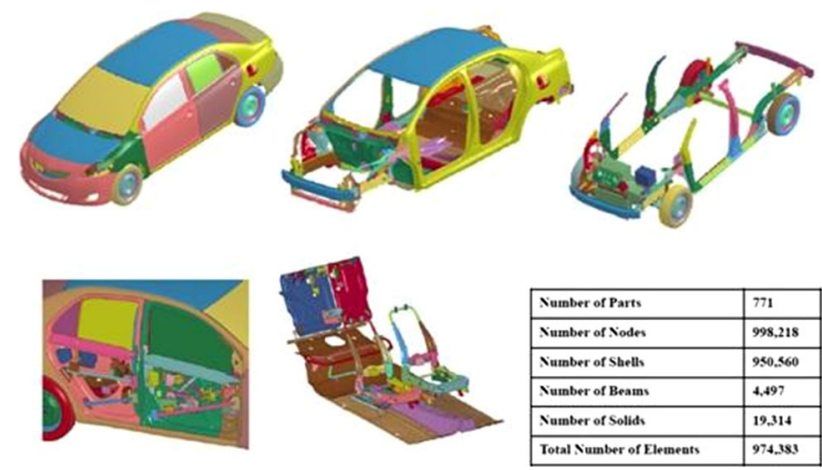

Fig. 3 Model information

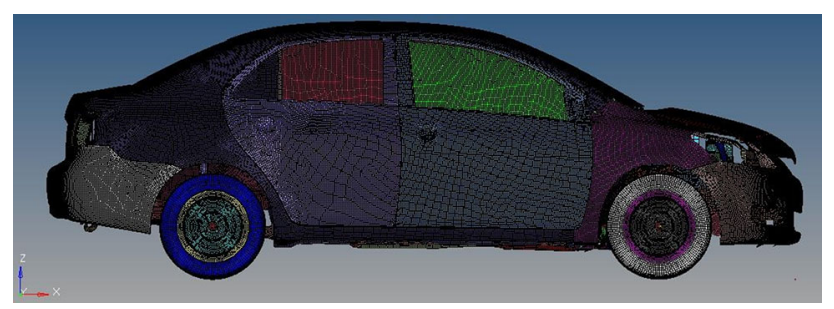

Fig. 4 Meshing generated for analysis
[11] finite element model, which is to be tested for IIHS bumper test protocol.

During frontal full overlap impact test the vehicle is given an initial velocity of $10 \mathrm{~km} / \mathrm{h}$. The impact barrier is mounted such that the forward most portion of the bottom edge of the barrier is $457 \mathrm{~mm}$ from the floor. Figures 5 and 6 show the finite element model and boundary conditions used during front full overlap impact test respectively. At impact, the vehicle centreline is aligned with the barrier centreline. The vehicle impacts the barrier at a speed of $10 \mathrm{~km} / \mathrm{h}$. The vehicle is analysed for the damage after vehicle comes to rest.

During front corner impact test the vehicle is given an initial velocity of $5 \mathrm{~km} / \mathrm{h}$. The impact barrier is mounted such that the forward most portion of the bottom edge of the barrier is $406 \mathrm{~mm}$ from the floor. Figures 7 and 8 show the finite element model and boundary conditions used for front corner impact test, respectively. At impact, the vehicle overlaps the lateral edge of the barrier by $15 \%$ (on side) of the vehicle's width as measured at the wheel walls (including mouldings and sheet metal protrusions) at the corresponding axle, that is, front axle for front corner tests and rear axle for rear corner tests. The vehicle impacts the barrier at a speed of $5 \mathrm{~km} / \mathrm{h}$. The vehicle is analyzed for the damage after vehicle comes to rest.

It is important to note that the assumptions used during impact test are: materials considered isotropic; all welds, bolts and riveted joints are assumed safe; buckle failure has not been considered and strain hardening effect in the material due to stamping of parts during manufacturing has not been considered.

\section{Results and Discussion}

As per IIHS regulation, in the first attempt the baseline finite element model [11] car is analysed for above mentioned two impact test cases. During frontal full overlap impact test it has been observed that the metallic bumper unable to protect

Table 1 Details of meshing and connections used for FE model

\begin{tabular}{ll}
\hline Mesh element summary & Connections used \\
\hline Number of parts: 771 & Beam connections: 4324 \\
Number of nodes: 998,218 & Nodal rigid body: 423 \\
Number of shells: 950,560 & Extra nodes set: 16 \\
Number of beams: 4497 & Joints: 14 \\
Number of solids: 19,314 & Rigid bodies: 2 \\
Total number of elements: 974,383 & Spot weld: 2862 \\
Weight, kg: 1078 (actual vehicle) & \\
\hline
\end{tabular}

Table 2 Material properties for metal bumper

\begin{tabular}{lllll}
\hline Material & Density, $\mathrm{kg} / \mathrm{m}^{3}$ & $\mathrm{E}, \mathrm{GPa}$ & Poissons ratio & $\mathrm{S}_{\mathrm{y}}, \mathrm{GPa}$ \\
\hline Mat24 & 7890 & 200 & 0.3 & 800 \\
\hline
\end{tabular}




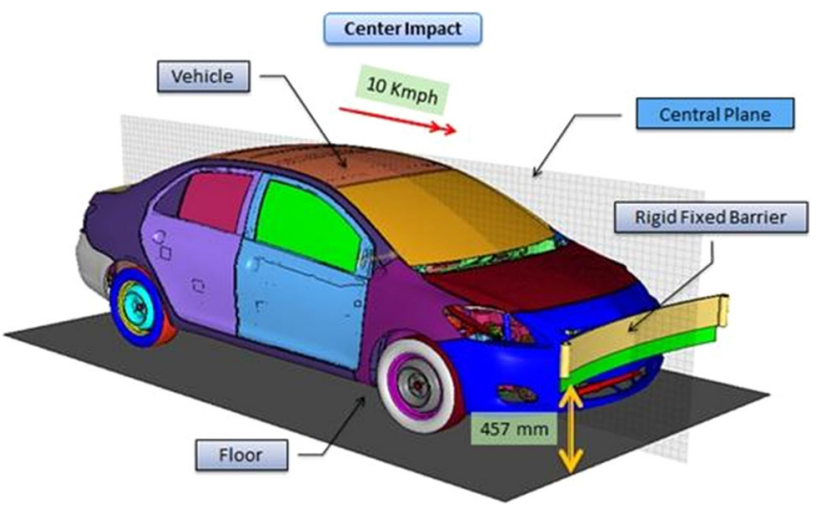

Fig. 5 Finite element model of frontal full overlap impact test

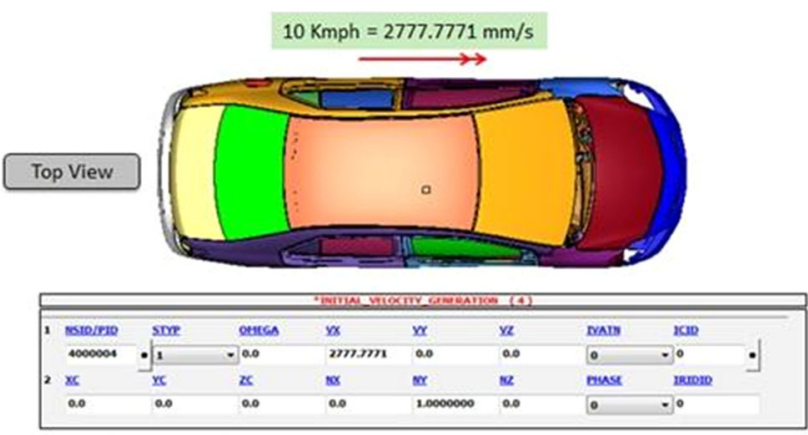

$$
\begin{aligned}
& \text { - PID - Part Set id } \\
& \text { - } \text { STYP - Part Set } \\
& \text { - VX - Velocity in Global X Direction. } \\
& \text { - VY - Velocity in Global X Direction. } \\
& \text { - Rest is not necessary for the analysis. }
\end{aligned}
$$

Fig. 6 Boundary conditions of frontal full overlap impact test

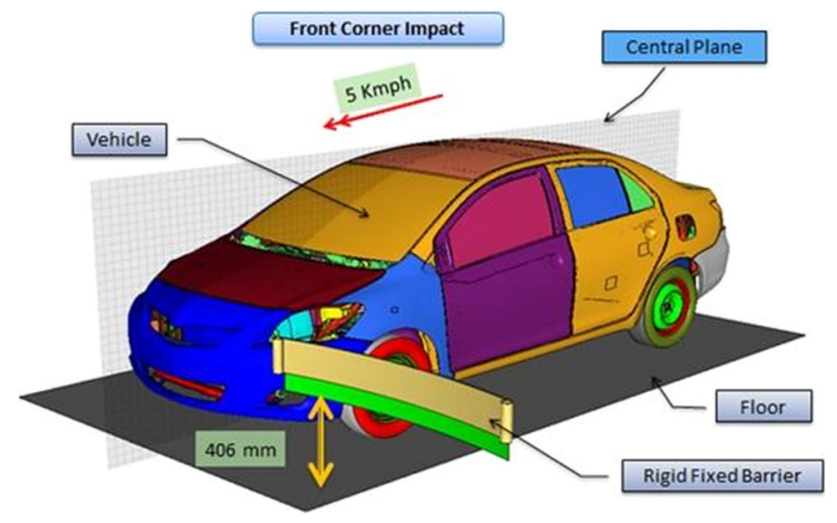

Fig. 7 Finite element model front corner impact test

the front radiator and nearby parts due to low strength. Figure 9 shows the simulation instances for front full overlap impact. It can be seen from Fig. 9 that the radiator has been damaged. Figures 10 and 11 show baseline metal bumper geometry (for reference) and the contours plot for plastic strain, respectively. The instantaneous deformation (at time $\mathrm{t}=0.15 \mathrm{~s}$ ) the maximum value of plastic strain of 0.2284 is found at centreline at point of impact.

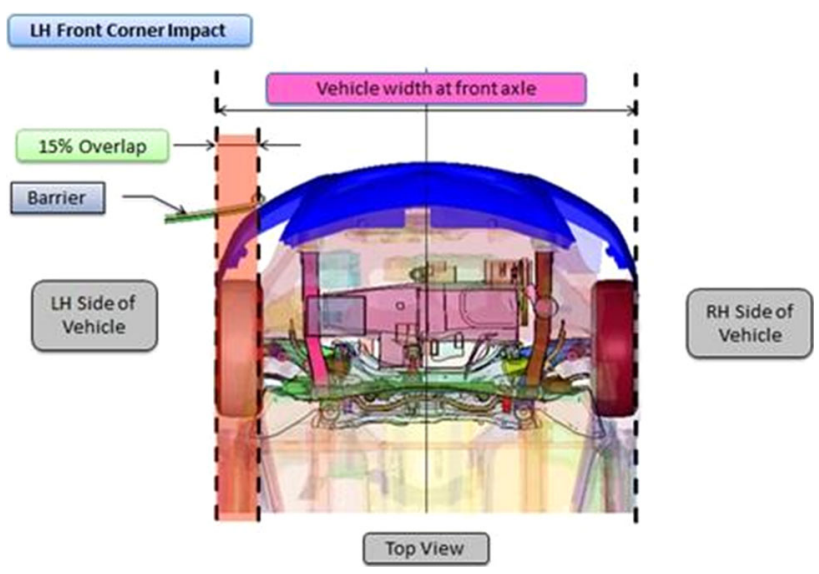

Fig. 8 Boundary conditions of front corner impact test

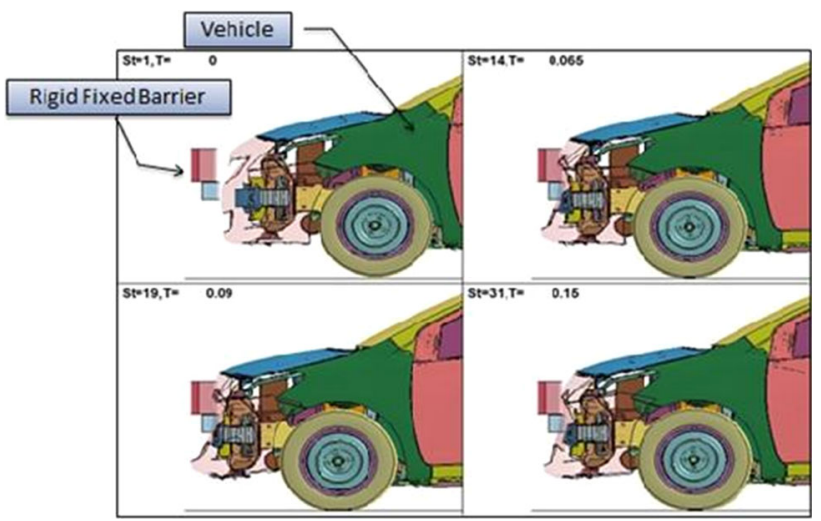

Fig. 9 Simulation instances for frontal full overlap impact test (baseline results)

Figures 12, 13 and 14 show the energy absorbed by metal bumper, left hand metal bumper bracket and right hand metal bumper bracket during frontal full overlap impact, left corner impact and right corner impact respectively. During front impact metal bumper absorbs almost all energy (2857.5 J) whereas both metal brackets have very less contribution (90.64, 94.75 J) as compared to the metal bumper. During corner impact, similar energy absorption percentage is observed however the numerical value is much less $(1.1548 \mathrm{~J})$ as compared frontal full overlap impact test.

From earlier result it is clear that modification in the bumper design is required in order to protect interior parts (for ex radiator, etc) during slow impact conditions. Designing of a new metal bumper has been attempted many modifications for various shapes, size and material. However, in this paper only significant result showing remarkable effects is discussed.

\section{Iteration 1: Modification in Shape (IOO1)}

In iteration 1 (I001), the shape of bumper is changed to absorb more energy during corner impact. The bumper is extended from sides, hence its length is increased from 


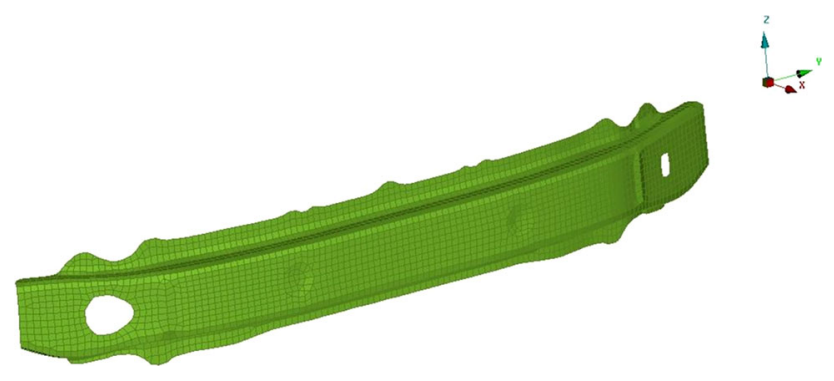

Fig. 10 Baseline bumper geometry (length $=1196 \mathrm{~mm}$, thickness $=1.5 \mathrm{~mm}$ )

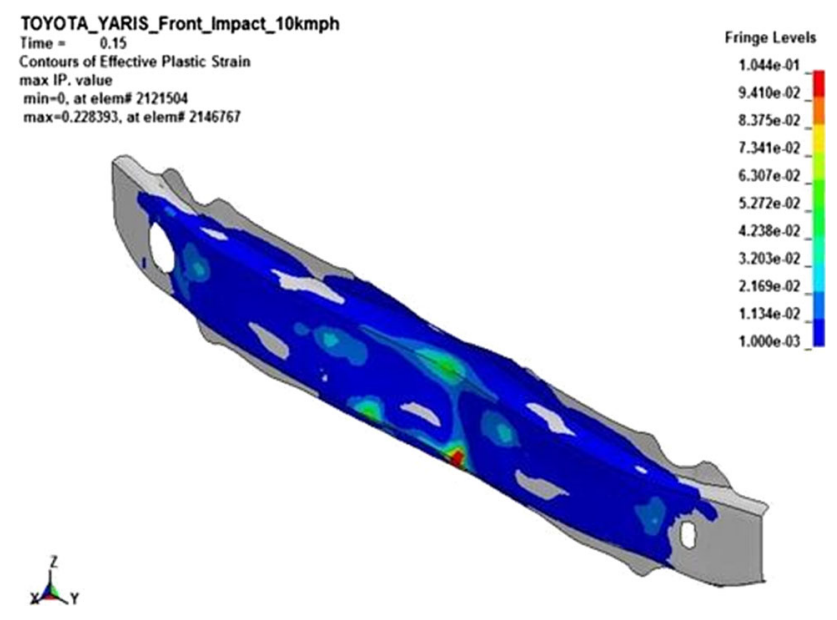

Fig. 11 Plastic strain plot of metal bumper beam (baseline results)

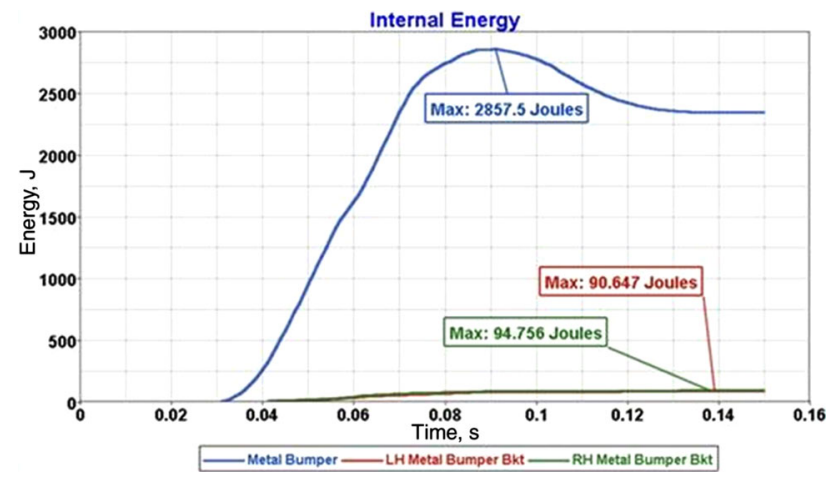

Fig. 12 Energy plot during frontal full overlap impact

1196 to $1586 \mathrm{~mm}$. Figures 15 and 16 show the schematic of modification added and actual bumper solid model of the metal bumper with extended portion. Note that the bumper thickness of $1.5 \mathrm{~mm}$ maintained as that of baseline bumper. All other properties are kept same as that of baseline model. The extended portion also provided with a thickness of $1.5 \mathrm{~mm}$ as that of baseline bumper thickness. The intention to extend the bumper beam in corners is to provide a part which will absorb energy during side impact.

From Fig. 17, it can be observed that the extended portion is not contributing during the frontal full overlap impact test and

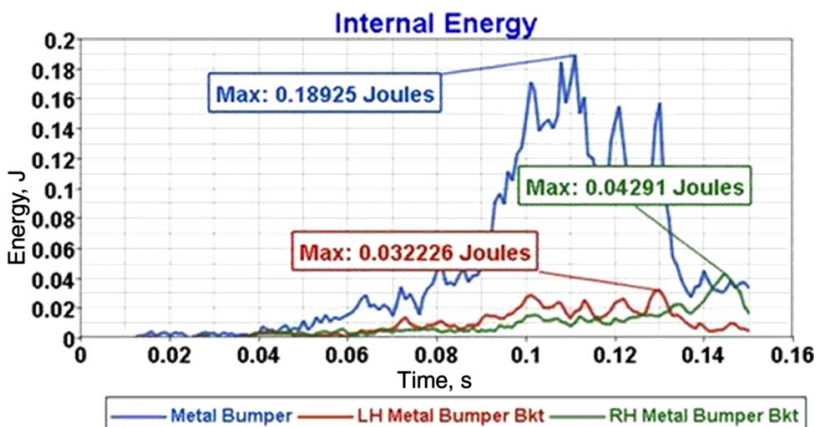

Fig. 13 Energy plot for left hand corner impact

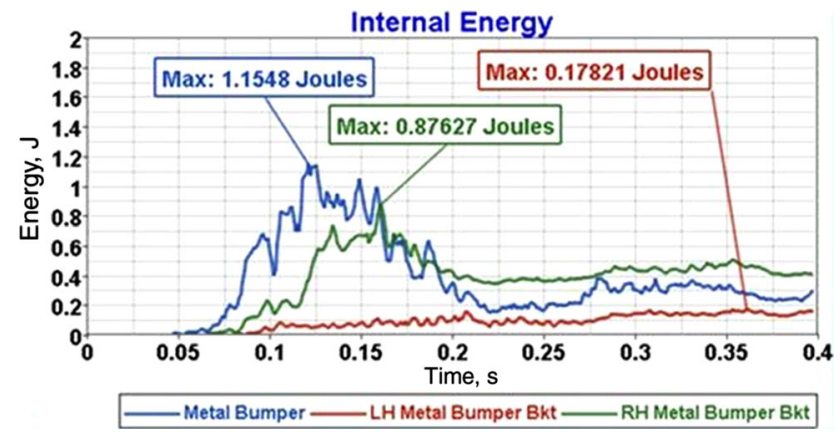

Fig. 14 Energy plot for right hand corner impact

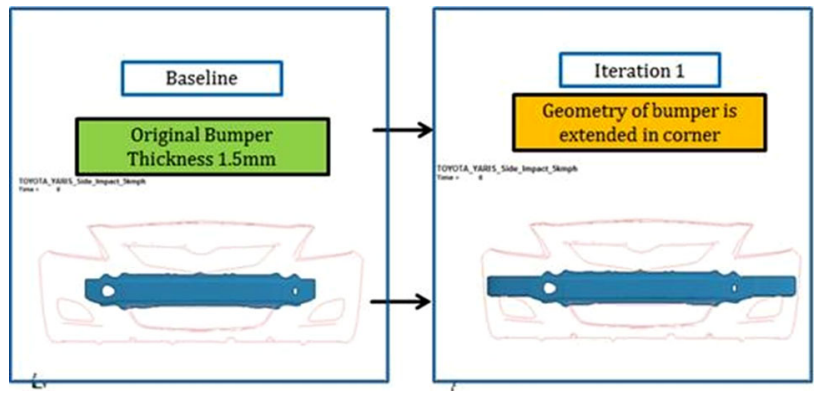

Fig. 15 Design changes during iteration 1 (I001)

the maximum plastic strain obtained is 0.2291 . The energy plot, shown in Fig. 18, is very much similar to that of baseline energy results (Fig. 12) with slight variation in energy absorption capacity of $2830.4 \mathrm{~J}$. However there is significant change can be seen from Figs. 19 and 20 which show the energy absorbed during corner impact test. The energy absorbed is increased to a value of $136.3 \mathrm{~J}$. This indicates that the modified bumper becomes preferable over baseline at least during side impact conditions. However in order to improve bumper strength further modifications are required.

\section{Iteration 2: Modification in Thickness (IOO2)}

During second iteration, as shown in Fig. 21, the iteration 1 (IOO1) bumper is modified for thickness. The thickness of 


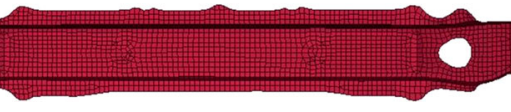

Fig. 16 Bumper geometry modified during iteration 1 (length $=1586 \mathrm{~mm}$, thickness $=1.5 \mathrm{~mm}$ )

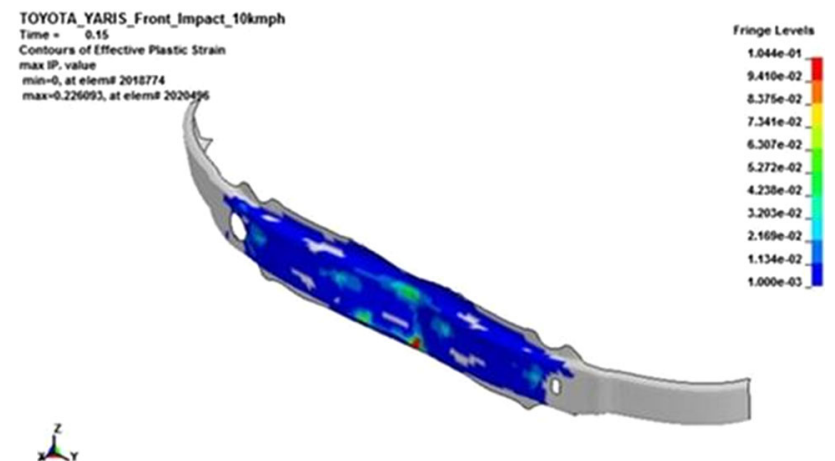

Fig. 17 Plastic strain plot of metal bumper beam (I001)

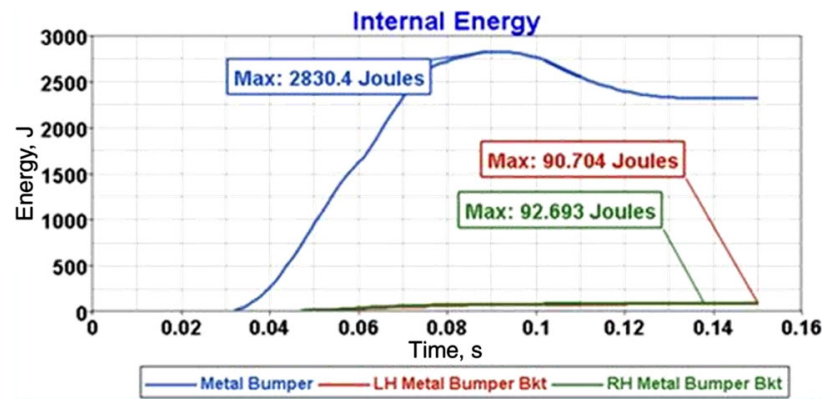

Fig. 18 Energy plot during frontal full overlap impact (I001)

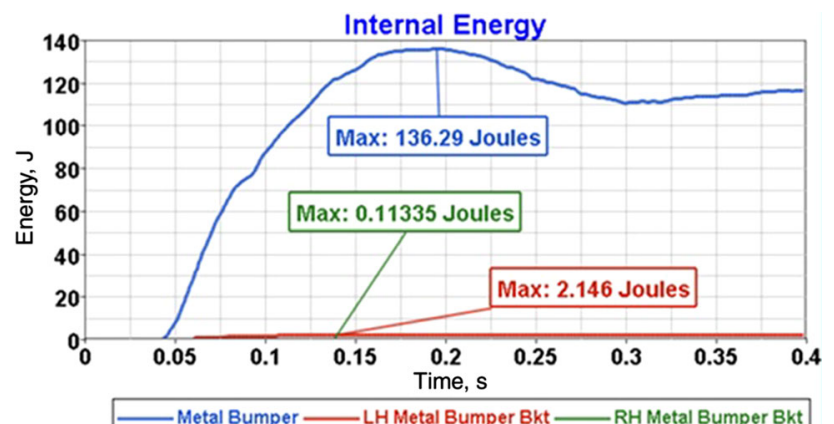

Fig. 19 Energy plot during left hand corner impact (I001)

metal bumper (having extended corner) is increased from 1.5 to $2 \mathrm{~mm}$ value. The increased thickness would provide more strength to the bumper.

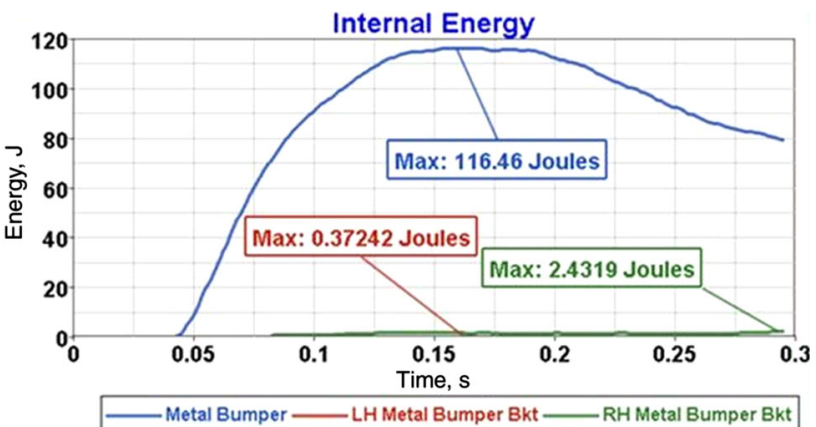

Fig. 20 Energy plot during right hand corner impact (I001)

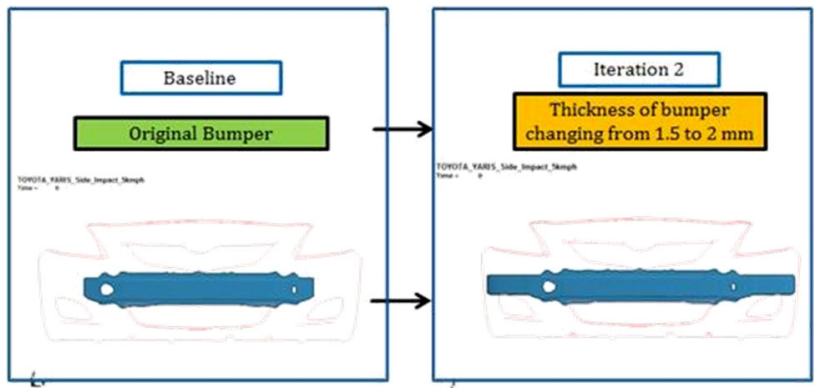

Fig. 21 Design changes during iteration 2 (I002)

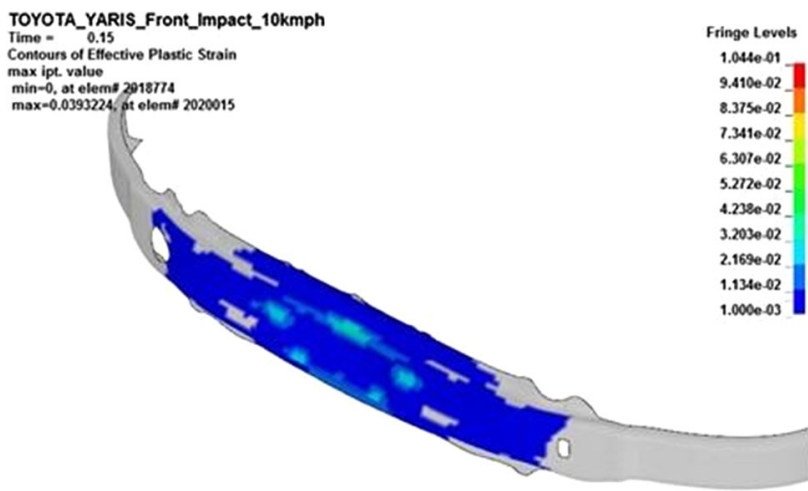

$\alpha_{r}^{2}$

Fig. 22 Plastic strain plot of metal bumper beam (I002)

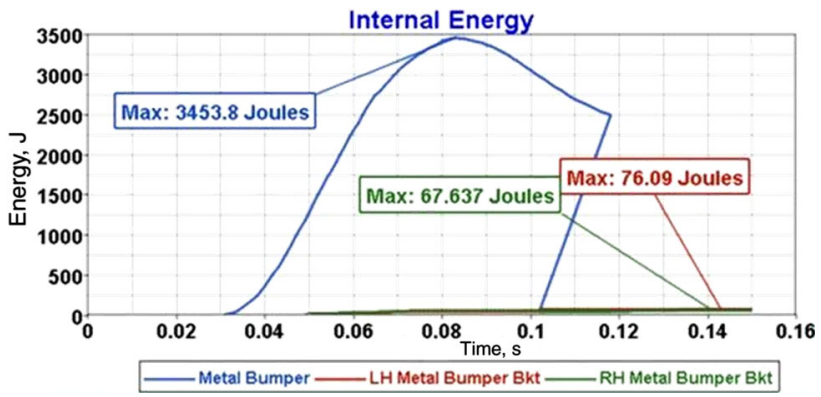

Fig. 23 Energy plot during frontal full overlap impact (I002) 


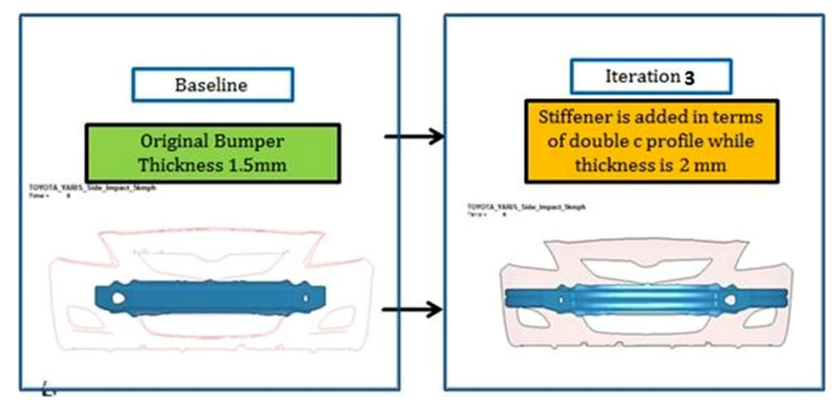

Fig. 24 Design changes during iteration 3 (I003)

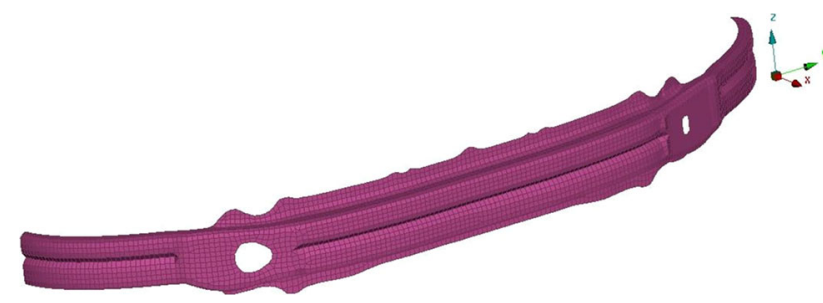

Fig. 25 Bumper geometry modified during iteration 3(I003) (length $=1586 \mathrm{~mm}$, thickness $=2 \mathrm{~mm}$ )

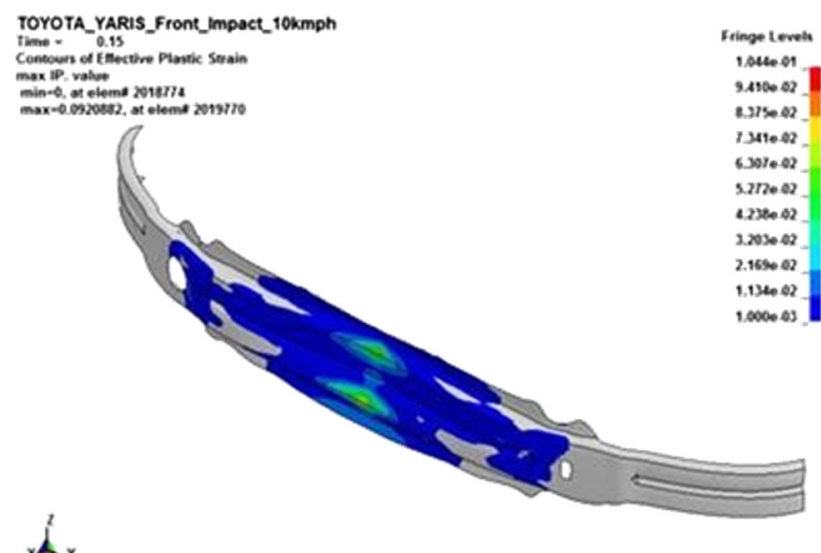

Fig. 26 Plastic strain plot of double c profile metal bumper beam

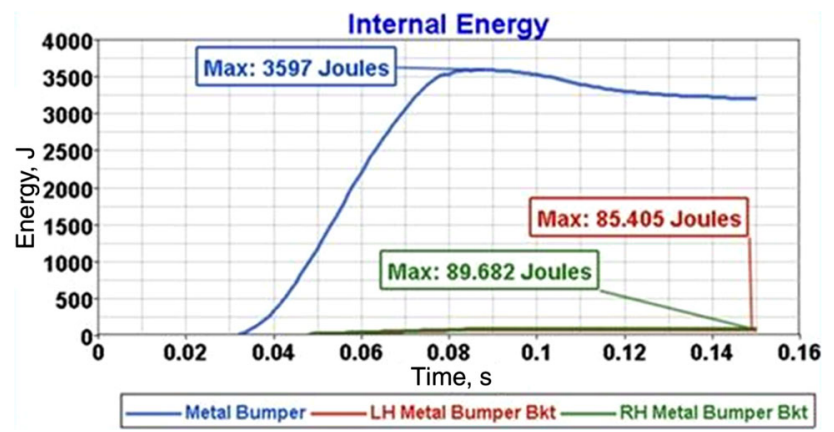

Fig. 27 Energy plot during frontal full overlap impact (I003)

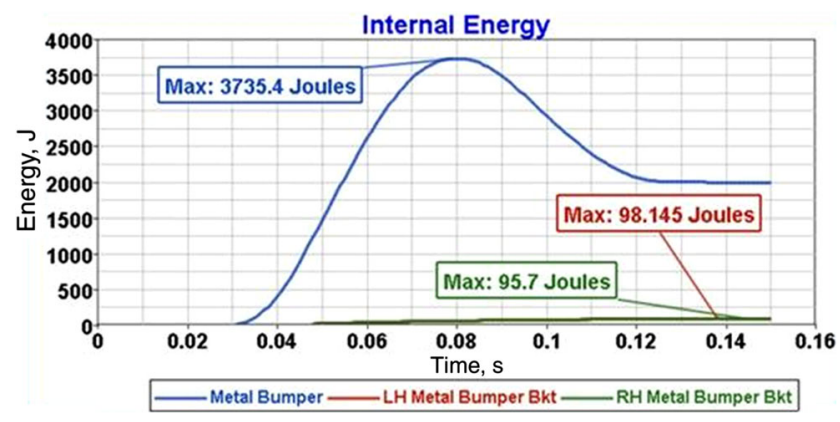

Fig. 28 Energy plot during frontal full overlap impact (I004)

Figure 22 shows the plastic strain contour plot of metal bumper beam. The maximum plastic strain is reduced to a value of 0.03933 , which indicates that the bumper become stiffer and have improved impact deformations resistant. Figure 23 shows the increase in energy absorption of metal bumper which is increased to a value of $3453.8 \mathrm{~J}$. However the metal bumper displacement happen during impact still causes the radiator damage.

\section{Iteration 3: Modification in Profile (IOO3)}

In third iteration the cross section shape of the metal bumper beam [iteration 2 (I002) bumper] is proposed to change from $\mathrm{C}$ profile to double $\mathrm{C}$ profile. As shown in Fig. 24, the central part of bumper will now have double $\mathrm{C}$ profile. Figure 25 shows the solid model for double $\mathrm{C}$ profile bumper having length of $1586 \mathrm{~mm}$ and thickness of $2 \mathrm{~mm}$ same that of equal to iteration 2 bumper. The changes in shape of a pro le will play very important role in energy absorption. Use of double $\mathrm{C}$ pro le makes the bumper stiffer and increases its energy absorption capacity. Figure 26 shows the plastic strain and Fig. 27 shows that the energy absorption during frontal full overlap impact test is now increased to $3595 \mathrm{~J}$.

\section{Iteration 4: Modification in Thickness (IOO4)}

In order to improve the strength further and to reduce the deformation during impact, which ultimately protects the radiator part, the thickness of iteration 3 (I003) bumper is increased to $2.5 \mathrm{~mm}$. As this pro le is stiffer than all previous models of metal bumper, it has the capacity to withstand the impact during frontal full overlap impact test and protects the radiator and front parts of vehicle effectively. Figure 28 show that the energy absorption is $3735.4 \mathrm{~J}$.

In Tables 3 and 4 show the comparative of energy absorbed by metal bumper during both the impact test. It can be seen that by increasing the stiffness either by increasing the bumper thickness or changing bumper shape which would results in less defection of bumper beam means bumper would take greater force to defect hence would able to absorb more work and energy (impact 
Table 3 Result summary of full overlap impact test

\begin{tabular}{llllc}
\hline Iteration & Design changes & $\begin{array}{l}\text { Energy absorbed } \\
\text { by metal bumper, J }\end{array}$ & $\begin{array}{l}\text { Energy absorbed } \\
\text { by LH bracket, J }\end{array}$ & $\begin{array}{c}\text { Energy absorbed } \\
\text { by RH bracket, J }\end{array}$ \\
\hline Baseline & Thickness $1.5 \mathrm{~mm}$ & 2857.5 & 90.64 & 94.756 \\
Iteration 1 & Geometry extended in corners & 2830.4 & 90.7 & 92.693 \\
Iteration 2 & Thickness change (1.5-2 mm) & 3453.8 & 76.09 & 67.63 \\
Iteration 3 & Shape changes (double C profile) & 3597 & 85.4 & 89.68 \\
Iteration 4 & Thickness change (1.5-2.5 mm) & 3735.4 & 98.14 & 95.7 \\
\hline
\end{tabular}

Table 4 Result summary of RH Corner impact test

\begin{tabular}{llccc}
\hline Iteration & Design changes & $\begin{array}{l}\text { Energy absorbed } \\
\text { by metal bumper, J }\end{array}$ & $\begin{array}{c}\text { Energy absorbed } \\
\text { by LH bracket, J }\end{array}$ & $\begin{array}{c}\text { Energy absorbed } \\
\text { by RH bracket, J }\end{array}$ \\
\hline Baseline & Thickness & 1.54 & 0.17 & 0.87 \\
Iteration 1 & Geometry extended in corners & 116.46 & 0.37 & 2.43 \\
Iteration 2 & Thickness change (1.5-2 mm) & 184.81 & 0.51 & 2.61 \\
Iteration 3 & Shape changes (double C profile) & 182.98 & 0.48 & 2.98 \\
Iteration 4 & Thickness change (1.5-2.5 mm) & 186.69 & 0.45 & 3.08 \\
\hline
\end{tabular}

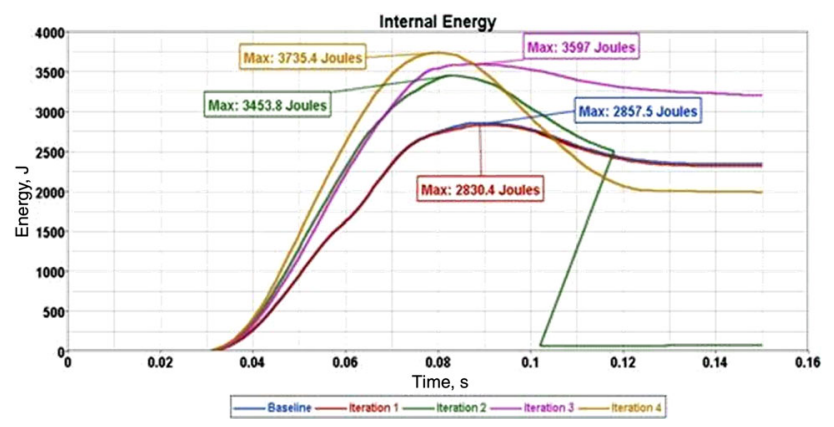

Fig. 29 Comparative study: energy plot during frontal full overlap impact test

energy). Figure 29 shows the comparative study for the energy plots during frontal full overlap impact test.

\section{Conclusion}

From the four iterations, it can be clear that the front metal bumper and bumper crush bracket share the major contributor to absorb crash energy in slow speed impact. It can be seen that the iterations made during the new design of metal bumper have improved the energy absorbing capacity almost by a factor of 1.3. It is also observed that the bumpers on colliding vehicles line-up geometrically so that engagement between each other happens during a slow speed crash. It has also been seen that the number of crush initiators, thickness of bumper, shape and pro le are the principal criterion's for designing the efficient crash energy management system.

Acknowledgements Authors are thankful to Defence Institute of Advanced Technology, Pune for providing required computational resources. Authors are also thankful to Automotive Research Association of India, Pune for their support extended. The authors wish to acknowledge The National Crash Analysis Center and The George Washington University for providing FE car model.

\section{References}

1. J. Marzbanrad, M. Alijanpour, M.S. Kiasat, Design and analysis of an automotive bumper beam in low-speed frontal crashes. Thin Walled Struct. 47, 902-911 (2009)

2. R. Hosseinzadeh, M.M. Shokrieh, L.B. Lessard, Parametric study of automotive composite bumper beams subjected to low-velocity impacts. Compos. Struct. 68(4), 419-427 (2005)

3. R.R. Magalhaes, C.H.O. Fontes, S.A.B. Vieira de Melo, Stress analysis of a front bumper fascia using the boundary element method. Eng. Anal. Bound. Elem. 36(8), 1296-1300 (2012)

4. P. Ge, N. Wang, C.Y.L. Stephen, An evolutionary modeling approach for automotive bumper system design and analysis. J. Comput. Inf. Sci. Eng. 2, 141-149 (2002)

5. M.M. Davoodi, S.M. Sapuan, D. Ahmad, A. Aidy, A. Khalina, M. Jonoobi, Concept selection of car bumper beam with developed hybrid bio-composite material. Mater. Des. 32(10), 4857-4865 (2011)

6. M.M. Davoodi, S.M. Sapuan, A. Aidy, N.A. Abu Osman, A.A. Oshkour, W.A.B.W. Abas, Development process of new bumper beam for passenger car: a review. Mater. Des. 40, 304-313 (2012)

7. S. Ahmed, G. Patil, Bumper shape optimization for pedestrian safety. IJERA 3(1), 1724-1732 (2013)

8. S. Sapuan, M. Maleque, M. Hameedullah, M. Suddin, N. Ismail, A note on the conceptual design of polymeric composite automotive bumper system. J. Mater. Process. Technol. 159(2), 145-151 (2003)

9. Insurance Institute for Highway Safety Bumper Test Protocol Version-VIII, 988 Dairy Rd, Ruckersville, VA 22968

10. National Highway Traffic Safety Administration (NHTSA), Laboratory test procedure for regulation Part 581, Bumper Standard Safety Assurance, 1990

11. Finite element model archive guideline, National Crash Analysis Centre (NCAC), http://www.ncac.gwu.edu/vml/models.html

12. Insurance Institute for Highway Safety Bumpers on mini and micro cars allow pricey damage in new IIHS tests. Status Rep. 44(6), (2009). http://www.iihs.org/iihs/sr/statusreport/article/44/6/1

13. IIHS Status Report 45(12), December 2, 2010, http://www. iihs.org/iihs/news/desktopnews 